\title{
Protective murine and human monoclonal antibodies against
}

\section{eczema vaccinatum}

\author{
Yoshiaki Tomimori ${ }^{1,4}$, Yuko Kawakami ${ }^{1}{ }^{\wedge}$, Megan M. McCausland ${ }^{2,5}$, Tomoaki Ando ${ }^{1}$, Lilia \\ Koriazova $^{3}$, Shinichiro Kato ${ }^{3,6}$, Toshi Kawakami ${ }^{1}$, and Shane Crotty ${ }^{2, \wedge}$ \\ ${ }^{1}$ Division of Cell Biology, La Jolla Institute for Allergy and Immunology (LIAI), La Jolla, CA 92037, \\ USA. \\ ${ }^{2}$ Division of Vaccine Discovery, La Jolla Institute for Allergy and Immunology (LIAI), La Jolla, CA \\ 92037, USA. \\ ${ }^{3}$ Kyowa Hakko Kirin California. La Jolla, CA, 92037, USA.
}

\begin{abstract}
Background-Eczema vaccinatum is the most common severe pathology associated with smallpox vaccination (vaccinia virus), occurring at high rates among individuals with a previous history of atopic dermatitis (atopic eczema).
\end{abstract}

Methods-Monoclonal antibodies capable of neutralizing vaccinia virus, anti-H3 and anti-B5, have been developed as a potential therapy for treatment of human eczema vaccinatum.

Results-Using a small animal model of eczema vaccinatum, here we demonstrate that both murine and fully human monoclonal antibodies effectively limit eczema vaccinatum disease, foreshortening both the disease kinetics and the severity of the erosive viral skin lesions.

Conclusions-These neutralizing antibodies would likely be effective at reducing or eliminating clinical disease in people with eczema vaccinatum or other severe side effects of the smallpox vaccine.

\section{Introduction}

Over the past decade there has been intensive interest in understanding immunity to poxviruses at multiple levels, with much of the effort focused on understanding the potent immunity elicited by the smallpox vaccine and the requirements for protection against smallpox and related pathogenic poxviruses [1]. From a clinical perspective, updating and stockpiling smallpox vaccine has been a major focus [2], as has been the development of anti-smallpox therapeutics. Two categories of anti-smallpox therapeutics have been extensively explored for potential biodefense use against smallpox itself or rare severe side effects of smallpox vaccination: small molecule drugs $[3,4][5]$ and monoclonal antibodies [6-9].

A clonal isolate of $\mathrm{VACV}_{\mathrm{NYCBOH}}$, ACAM2000, has now been developed as a cell culture derived smallpox vaccine, with a comparable immunogenicity and safety profile to Dryvax [2]. Smallpox vaccine "take" for classic $\mathrm{VACV}_{\mathrm{NYCBOH}}$, ACAM2000, or Lister is observed

\footnotetext{
^Corresponding authors: 9420 Athena Circle, La Jolla, CA 92037, shane@liai.org, (858) 752-6816, (858) 752-6993 (fax) or yuko@liai.org, (858) 752-6814, (858) 752-6986 (fax).

${ }_{4}^{4}$ Current address: Asubio Pharma, Kyoto, Japan

${ }^{5}$ Current address: Emory University School of Medicine, Atlanta GA, 30324

${ }^{6}$ Current address: Kyowa Hakko Kirin, Tokyo, Japan
} 
as the formation of a pustule starting on approximately day 5 post-vaccination and lasting for $1-2$ weeks thereafter $[10,11]$. The vaccine provides outstanding immunity, but causes a variety of side effects that have been reason for concern [12]. Common side effects include fever and satellite pocks (additional pustules near the primary pustule)[11,12]. More severe side effects include progressive vaccinia, generalized vaccinia, encephalitis, vaccinia keratitis, and eczema vaccinatum [12]. Eczema vaccinatum is a severe and difficult to treat pathology that occurs in some immunized humans with a previous history of atopic dermatitis (eczema). Currently, VIG (Vaccinia Immune Globulin) is the only licensed therapeutic to treat severe side effects of smallpox vaccination [13]. In addition, VIG has shown efficacy against smallpox itself, in clinical trials in the early 1960s [14].

Unfortunately, VIG is a poorly characterized, variable human product that is of limited potency $[13,14]$. These limitations of VIG have led to great interest in the development of an alternative high potency anti-vaccinia and anti-smallpox immunotherapy.

Poxviruses have two distinct virion forms, Intracellular Mature Virions (MV, IMV) and Extracellular Enveloped Virions (EV, EEV), each with different biology. The two virion forms do not share any surface proteins, and therefore the virion forms are immunologically distinct and are not neutralized by antibody of a single specificity [1]. VIG contains both anti-MV and anti-EV antibodies [15-17]. Therefore, we have pursued development of a VIG replacement therapeutic product containing one anti-MV mAb and one anti-EV mAb, each capable of neutralizing their respective virion form [6]. We first identified murine and human neutralizing antibodies against the MV surface antigen $\mathrm{H} 3$ [16,17], and EV surface antigen B5 [7,18], both of which neutralize in the presence of complement. We further demonstrated that B5 antibodies are highly effective at catalyzing complement mediated killing of VACV infected cells as an additional antiviral mechanism $[7,18]$. Recently, we demonstrated that anti-H3 and anti-B5 murine and human mAbs were significantly more effective than VIG at extending lifespan of immunodeficient SCID mice infected with VACV [6]. As a second model of treatment efficacy, we have now examined the efficacy of anti-H3 and anti-B5 mAbs against VACV in a new mouse model of eczema vaccinatum.

\section{Materials and Methods}

\section{Viruses}

$\mathrm{VACV}_{\mathrm{WR}}$ (Western Reserve) stocks were grown as described [16,17]. The ACAM2000 stock was generated by single passage amplification in HeLa cells of ACAM2000® vaccine virus (Acambis, UK).

\section{Mouse infections}

$\mathrm{NC} / \mathrm{Nga}$ mice were used in all experiments [19]. Eczematous skin lesions were induced as described previously [20]. Briefly, back skin were shaved and dermatitis was induced by 2 rounds of treatment with Dermatophagoides farinae extract (Der f, Greer Laboratories) and Staphylococcal enterotoxin B (SEB) (Sigma-Aldrich). During this treatment, the back skin was occluded with a bandage that was removed the following week. Clinical scores of eczematous skin lesions are based on severity ( 0 , no signs; 1 , mild; 2 , intermediate; 3 , severe) of four signs (redness, bleeding, eruption and scaling). Scoring of skin lesions was performed in a blind manner. VACV (Western Reserve strain or ACAM2000, 106 PFU per $3 \mu \mathrm{l}$ ) was dropped on the center of skin lesions of mice with a clinical score of $\geq 7$ (eczematous group) followed by pricking 15 times with a $27 \mathrm{G}$ needle. In some experiments, a cohort (normal group) of age and sex-matched mice with healthy skin was also infected at the same anatomical site. After VACV infection on day 0 , mice were monitored daily in a blind manner and body weight and size of the skin lesion were measured. Murine antiVACV mAbs anti-B5 \#B126 and/or anti-H3 \#41 were intraperitoneally or intravenously 
injected 24 hours before or 12 hours after VACV infection. Animals were housed in microisolator cages in ventilated racks. All animal experiments were conducted using the Institutional Animal Care and Use Committee approved animal protocols.

\section{Antibodies}

Anti-B5 IgG2a clone B126 and anti-H3 IgG2a clone 41 were generated and produced as described $[6,18]$. Fully human monoclonal antibodies h101 and hV26 were generated and produced as described $[6,7]$.

\section{Statistical analysis}

Statistical analysis was carried out using Prism 5.0 software (Graphpad). Size of skin lesions, incidence and changes of body weight were analyzed with unpaired, two-tailed Ttest. Cumulative skin lesion burden (e.g. Fig. 2B) was calculated as the area under the curve (AUC) of skin lesion size over time and analyzed by unpaired, two-tailed T-test. P $<0.05$ was considered statistically significant. Disease incidence (prevalence) statistical significance was determined by Fisher's Exact Test.

\section{Results}

\section{$\mathrm{NC} / \mathrm{Nga}$ eczema vaccinatum model}

Eczema vaccinatum is a severe, potentially fatal, side effect of smallpox vaccination that occurs in some vaccinees with a previous history of eczema. The reason for this striking and peculiar pathology of VACV has been unclear. Previously, no small animal model of this clinical disease had been available. We recently developed a mouse model of eczema vaccinatum [21]. NC /Nga mice are susceptible to atopic dermatitis [19,20]. In this system, $\mathrm{NC} / \mathrm{Nga}$ mice are shaved and atopic dermatitis is induced with allergen (Figure 1A-B). Eczematous mice are then infected intradermally with vaccinia virus $\left(\mathrm{VACV}_{\mathrm{WR}}\right)$, and virusinduced skin lesions are observed (Figure 1C). Viral titers in the skin lesions are $>100$-fold increased in eczematous mice [21], and the disease is strongly associated with defective NK cell activity and elevated IL-17 levels [21]. The infection and eczema vaccinatum lesions are self resolved after two weeks (Figure 2A). Eczema vaccinatum can also be induced with vaccine strain viruses, though the skin lesions are less severe, consistent with the low replicative potential of $\mathrm{VACV}_{\mathrm{NYCBOH}}$ related strains (e.g., ACAM2000) in mice (Figure 1D).

\section{Protective efficacy of single murine anti-VACV mAbs}

The protective efficacy of murine mAbs against VACV at treating eczema vaccinatum was first tested in a pre-exposure model, wherein eczematous mice were injected with a single $200 \mu \mathrm{g}$ anti-H3 or anti-B5 mAb one day prior to intradermal infection with VACV. It was unclear whether antibodies would be effective against intradermal infection with VACV, particularly given the defective NK cells, which are important for early control of the virus. Development of skin lesions was delayed in $\mathrm{mAb}$ treated mice (Figure 2A, C) and severity of the lesions was substantially reduced (anti-B5, P $<0.01$ at all timepoints day 2 to 14 . Anti-H3, $\mathrm{P} \leq 0.01$ at all timepoints day 2 to 13 , except day 3 . $\mathrm{P}<0.05$ at days 3 and 14.) (Figure 2A). Disease incidence was moderately reduced, from $100 \%$ to $80 \%$ in anti-H3 or anti-B5 treated mice (Figure 2C). Lesion disease burden was significantly reduced after treatment with either anti-H3 mAb $(\mathrm{P}<0.001)$ or anti-B5 mAb $(\mathrm{P}<0.001)$. Minimal change in body weight was observed in all groups (Figure 2D), consistent with our previous work [21].

Post-exposure prophylaxis efficacy of the antibodies was then tested. Eczematous mice were infected intradermally with VACV. Intravenous injection of anti-H3 or anti-B5 mAb was 
done 12 hours after infection. Anti-B5 treatment was still able to delay lesion development $(\mathrm{P}<0.05$, day 3)(Figure 3A, C), reduce the disease incidence (Figure 3C), and reduce the overall lesion disease burden $(\mathrm{P}<0.05)$ (Figure 3B). Anti-H3 was not able to reduce disease incidence when provided after infection (day $3, \mathrm{P}=\mathrm{NS}$ )(Figure 3C), nor did it provide statistically significant reduction in overall lesion disease burden (Figure 3B). Anti-H3 treatment post-infection did provide some reduction in lesions, though this trend was not statistically significant (Figure 3A, B). These data in combination with the pre-exposure data of Figure 2 indicate that neutralization of VACV MV virions by $\mathrm{H} 3$ is more effective at the time of inital exposure to virus than after initiation of infection. This is likely due to lack of neutralization of the EV form.

\section{Protective efficacy of murine anti-VACV mAb combination therapy}

Given that anti-B5 exhibited good efficacy and anti-H3 exhibited some efficacy in postexposure treatment, a combination of anti-B5 and anti-H3 was then tested. This combination neutralizes both EV and MV virions and is the proposed regimen for humans [6]. Mice treated with anti-B5 mAb alone post-exposure were again partially protected from disease, observed by reduction in peak skin lesion size ( $\mathrm{P}<0.05$, each timepoint days 4 to 7$)$ (Fig. $4 \mathrm{~A})$, delayed onset of disease $(\mathrm{P}=0.01)(\mathrm{Fig} .4 \mathrm{C})$, and overall lesion disease burden reduction $(\mathrm{P}<0.05)$ (Fig. 4B). Mice treated with the anti-B5/H3 combination were in much better health than mice treated with anti-B5 alone. Greatly reduced lesion sizes $(\mathrm{P} \leq 0.01$, days 4 to 14)(Fig. 4A) and overall lesion disease burden was observed in mice receiving the anti-B5/H3 combination ( $\mathrm{P}<0.01$ vs. control; $\mathrm{P}<0.05$ vs. anti-B5 mAb alone)(Fig. 4B). Most strikingly, disease was completely prevented in approximately half of the animals receiving the anti-B5/H3 mAb combination (Fig. 4C). This was somewhat unexpected, given the earlier poor efficacy of anti-H3 mAb single therapy post-exposure (Fig. 3). Together these data (Fig. 3, 4) indicate that targeting both an EV and MV neutralization target results in improved efficacy in vivo.

\section{Protective efficacy of human anti-VACV mAbs}

Given the successful activities of murine anti-B5 and anti-H3 mAbs against VACV in vitro and in vivo in earlier studies [6,18] and against eczema vaccinatum (Fig. 2-4), we developed fully human anti-B5 and anti-H3 mAbs as potential therapeutics [6,7]. Using the eczema vaccinatum model, mice were treated with $m A b s$ after initiation of intradermal VACV infection. A single inoculation of human anti-B5 $\mathrm{mAb}$ was provided alone or in combination with a human anti-H3 mAb. Mice that received post-exposure treatment with human anti-B5 $\mathrm{mAb}$ alone were partially protected from disease, observed by reduction in peak skin lesion size $(\mathrm{P}<0.05$, day 4)(Fig. 5A-B), delayed onset of disease $(\mathrm{P}<0.05)$ (Fig. 5A), lower disease incidence (Fig. 5C), and overall lesion disease burden reduction $(\mathrm{P}<0.01)$ (Fig. 5B). Mice treated with the human anti-B5/H3 mAb combination exhibited protection. Greatly reduced lesion sizes ( $\mathrm{P} \leq 0.01$, days 2 to 12$)$ (Fig. 5A) and overall lesion disease burden was observed in mice receiving the anti-B5/H3 combination ( $\mathrm{P}<0.001$ vs. control; $\mathrm{P}<0.01$ vs. anti-B5 mAb alone)(Fig. 5A). Disease was completely prevented in approximately half of the animals receiving the anti-B5/H3 mAb combination $(\mathrm{P}<0.01)$ (Fig. 5C). Together these data recapitulate our murine $\mathrm{mAb}$ findings shown in Figure 4 that targeting both an EV and MV neutralization target results in increased protection in vivo.

\section{Discussion}

Our primary goal here was preclinical validation of a post-exposure prophylactic human anti-MV and anti-EV mAb combination treatment that would be a replacement for VIG as treatment for eczema vaccinatum and other severe side effects of vaccinia immunization, and potentially for treatment of smallpox infection itself. The rationale for this approach is 
that mAbs can have much higher specific activity than polyclonal Abs, and recombinant human $\mathrm{mAbs}$ can be manufactured in virtually unlimited quantities, under well defined conditions. Here we show that neutralizing mAbs against VACV can be highly efficacious at ameliorating or eliminating eczema vaccinatum in a small animal model. Eczema vaccinatum is associated with poor NK cell activity, and high levels of IL-17, resulting in vastly increased viral loads and progressive skin lesion development [21]. Our data indicate that reduction in the viral load by neutralizing antibodies offsets the defective antiviral activity of the NK cells, likely resulting in clearance of the infection by normal innate and adaptive mechanisms of the immune system, independent of NK cells. Reduction in viral load by these neutralizing antibodies would therefore be likely to be effective at reducing or eliminating clinical disease in people with eczema vaccinatum or other severe side effects of the smallpox vaccine.

We speculate that the combination of anti-H3 and anti-B5 mAbs provides increased protection in this eczema vacinatum model, and in an immunodeficient mouse model, via several mechanisms of action. The anti-H3 mAb neutralizes MV virions [6], which are released from dead cells in abundance. The anti-B5 mAb neutralizes the other virus form, $\mathrm{EV}$ virions, in a complement dependent manner [7,18]. In addition, anti-B5 mAbs direct the complement-mdeiated killing of VACV infected cells, due to expression of B5 on the surface of infected cells $[7,18]$. This is a potent mechanism of eliminating reservoirs of replicating virus. It is also plausible that the anti-H3 mAbs specifically enhance the function of anti-B5. Anti-B5 mAbs can direct killing of VACV infected cells, but that then can release a bolus of MV virions, and the presence of anti-H3 mAbs eliminates that problem. In addition, the outer membrane of EV particles is notoriously fragile [22-25], and binding of anti-B5 mAb to EV virions may, in some cases, disrupt the EV membrane and release the infectious MV particle inside. Again, the presence of anti-H3 mAb compensates for this problem by simultaneously neutralizing the MV.

Given the efficacy of these mAbs in three animal models-eczema vaccinatum, respiratory VACV [7], and immunodeficient SCID mice [6] — and their enhanced efficacy in comparison to VIG [6], these human mAbs may also be efficacious against smallpox.

\section{Acknowledgments}

This work was partly funded by NIH NIAID AI63107, NIH NIAID AI077953, a Pew Scholar Award, and LIAI Institutional Funds to SC. This works was partly funded by Kyowa Hakko Kirin California internal funds to SK.

\section{References}

1. Amanna IJ, Slifka MK, Crotty S. Immunity and immunological memory following smallpox vaccination. Immunol Rev 2006;211:320-337. [PubMed: 16824139]

2. Greenberg RN, Kennedy JS. ACAM2000: a newly licensed cell culture-based live vaccinia smallpox vaccine. Expert Opin Investig Drugs 2008;17:555-564.

3. Grosenbach DW, Berhanu A, King DS, Mosier S, Jones KF, Jordan RA, Bolken TC, Hruby DE. Efficacy of ST-246 versus lethal poxvirus challenge in immunodeficient mice. Proc Natl Acad Sci U S A 107:838-843. [PubMed: 20080762]

4. Huggins J, Goff A, Hensley L, Mucker E, Shamblin J, Wlazlowski C, Johnson W, Chapman J, Larsen T, Twenhafel N, Karem K, Damon IK, Byrd CM, Bolken TC, Jordan R, Hruby D. Nonhuman primates are protected from smallpox virus or monkeypox virus challenges by the antiviral drug ST-246. Antimicrob Agents Chemother 2009;53:2620-2625. [PubMed: 19349521]

5. Parker S, Touchette E, Oberle C, Almond M, Robertson A, Trost LC, Lampert B, Painter G, Buller RM. Efficacy of therapeutic intervention with an oral ether-lipid analogue of cidofovir (CMX001) in a lethal mousepox model. Antiviral Res 2008;77:39-49. [PubMed: 17904231] 
6. McCausland M, Benhnia M, Crickard L, Laudenslager J, Granger S, Tahara T, Kubo R, Koriazova L, Kato S, Crotty S. Combination therapy of vaccinia virus infection with human anti-H3 and antiB5 monoclonal antibodies in a small animal model. Antiviral Therapy. 2010 in press.

7. Benhnia MR, McCausland MM, Laudenslager J, Granger SW, Rickert S, Koriazova L, Tahara T, Kubo RT, Kato S, Crotty S. Heavily isotype-dependent protective activities of human antibodies against vaccinia virus extracellular virion antigen B5. J Virol 2009;83:12355-12367. [PubMed: 19793826]

8. Chen Z, Earl P, Americo J, Damon I, Smith SK, Yu F, Sebrell A, Emerson S, Cohen G, Eisenberg RJ, Gorshkova I, Schuck P, Satterfield W, Moss B, Purcell R. Characterization of chimpanzee/ human monoclonal antibodies to vaccinia virus A33 glycoprotein and its variola virus homolog in vitro and in a vaccinia virus mouse protection model. Journal of Virology 2007;81:8989-8995. [PubMed: 17581986]

9. Chen Z, Earl P, Americo J, Damon I, Smith SK, Zhou Y-H, Yu F, Sebrell A, Emerson S, Cohen G, Eisenberg RJ, Svitel J, Schuck P, Satterfield W, Moss B, Purcell R. Chimpanzee/human mAbs to vaccinia virus $B 5$ protein neutralize vaccinia and smallpox viruses and protect mice against vaccinia virus. Proc Natl Acad Sci USA 2006;103:1882-1887. [PubMed: 16436502]

10. Fenner F, Henderson DA, Arita I, Jezek z, Ladnyi i. Smallpox and its Eradication 2001:4.

11. Fulginiti VA, Papier A, Lane JM, Neff JM, Henderson DA. Smallpox vaccination: a review, part I. Background, vaccination technique, normal vaccination and revaccination, and expected normal reactions. Clin Infect Dis 2003;37:241-250. [PubMed: 12856217]

12. Fulginiti VA, Papier A, Lane JM, Neff JM, Henderson DA. Smallpox vaccination: a review, part II. Adverse events. Clin Infect Dis 2003;37:251-271. [PubMed: 12856218]

13. Wittek R. Vaccinia immune globulin: current policies, preparedness, and product safety and efficacy. Int J Infect Dis 2006;10:193-201. [PubMed: 16564720]

14. Hopkins RJ, Lane JM. Clinical efficacy of intramuscular vaccinia immune globulin: a literature review. Clin Infect Dis 2004;39:819-826. [PubMed: 15472814]

15. Davies DH, Molina DM, Wrammert J, Miller J, Hirst S, Mu Y, Pablo J, Unal B, Nakajima-Sasaki R, Liang X, Crotty S, Karem KL, Damon IK, Ahmed R, Villarreal L, Felgner PL. Proteome-wide analysis of the serological response to vaccinia and smallpox. Proteomics 2007;7:1678-1686. [PubMed: 17443847]

16. Davies DH, McCausland MM, Valdez C, Huynh D, Hernandez JE, Mu Y, Hirst S, Villarreal L, Felgner PL, Crotty S. Vaccinia virus H3L envelope protein is a major target of neutralizing antibodies in humans and elicits protection against lethal challenge in mice. J Virol 2005;79:11724-11733. [PubMed: 16140750]

17. Benhnia MR, McCausland MM, Su HP, Singh K, Hoffmann J, Davies DH, Felgner PL, Head S, Sette A, Garboczi DN, Crotty S. Redundancy and plasticity of neutralizing antibody responses are cornerstone attributes of the human immune response to the smallpox vaccine. J Virol 2008;82:3751-3768. [PubMed: 18234801]

18. Benhnia MR-E-I, McCausland MM, Moyron J, Laudenslager J, Granger S, Rickert S, Koriazova L, Kubo R, Kato S, Crotty S. Vaccinia virus extracellular enveloped virion neutralization in vitro and protection in vivo depend on complement. Journal of Virology 2009;83:1201-1215. [PubMed: 19019965]

19. Matsuda H, Watanabe N, Geba GP, Sperl J, Tsudzuki M, Hiroi J, Matsumoto M, Ushio H, Saito S, Askenase PW, Ra C. Development of atopic dermatitis-like skin lesion with IgE hyperproduction in NC/Nga mice. Int Immunol 1997;9:461-466. [PubMed: 9088984]

20. Kawakami Y, Yumoto K, Kawakami T. An improved mouse model of atopic dermatitis and suppression of skin lesions by an inhibitor of Tec family kinases. Allergol Int 2007;56:403-409. [PubMed: 17713360]

21. Kawakami Y, Tomimori Y, Yumoto K, Hasegawa S, Ando T, Tagaya Y, Crotty S, Kawakami T. Inhibition of NK cell activity by IL-17 allows vaccinia virus to induce severe skin lesions in a mouse model of eczema vaccinatum. J Exp Med 2009;206:1219-1225. [PubMed: 19468065]

22. Moss, B. Poxviridae: The Viruses and their Replication. In: Knipe, D.; Howley, P.; Griffin, D.; Lamb, R., editors. Fundamental Virology. 2006. 
23. Lustig S, Fogg C, Whitbeck JC, Moss B. Synergistic neutralizing activities of antibodies to outer membrane proteins of the two infectious forms of vaccinia virus in the presence of complement. Virology 2004;328:30-35. [PubMed: 15380355]

24. Smith GL, Vanderplasschen A, Law M. The formation and function of extracellular enveloped vaccinia virus. J Gen Virol 2002;83:2915-2931. [PubMed: 12466468]

25. Law M, Carter GC, Roberts KL, Hollinshead M, Smith GL. Ligand-induced and nonfusogenic dissolution of a viral membrane. Proc Natl Acad Sci USA 2006;103:5989-5994. [PubMed: 16585508] 
A

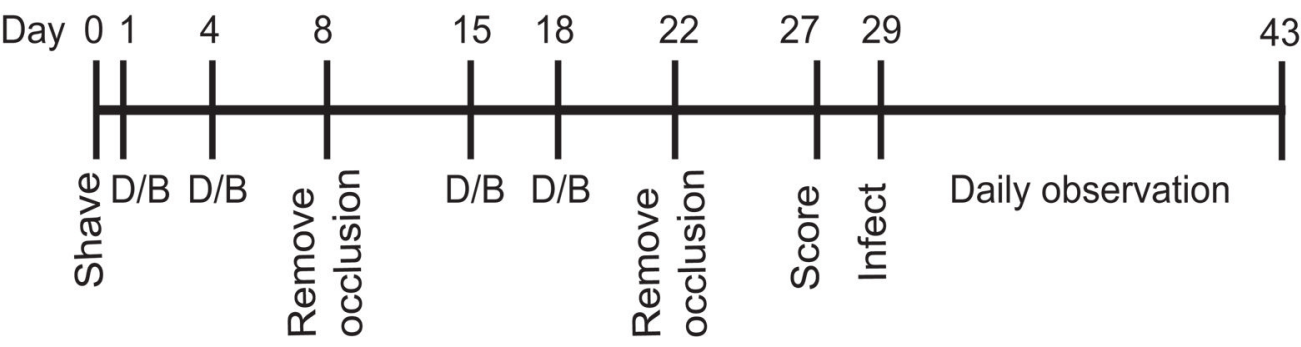

B

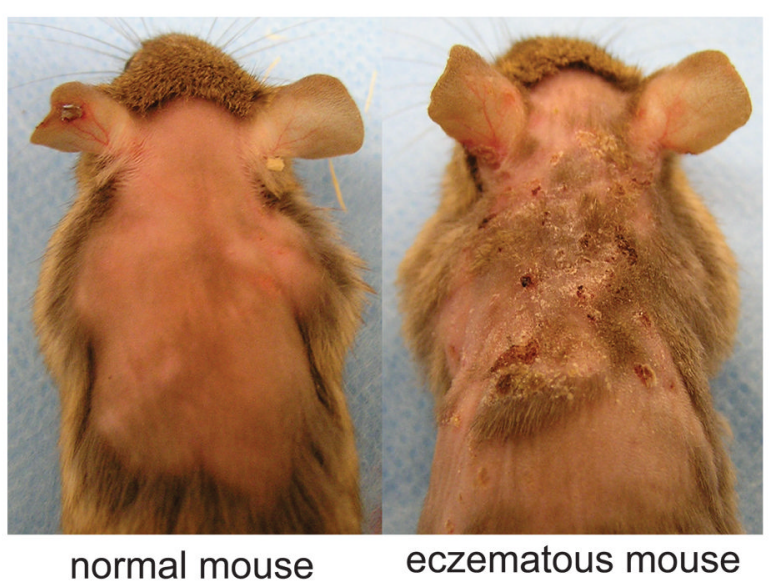

C

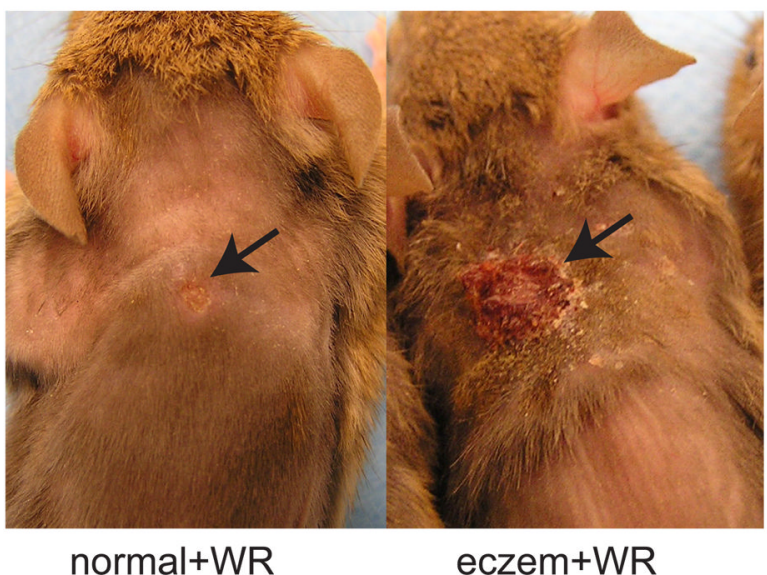

D

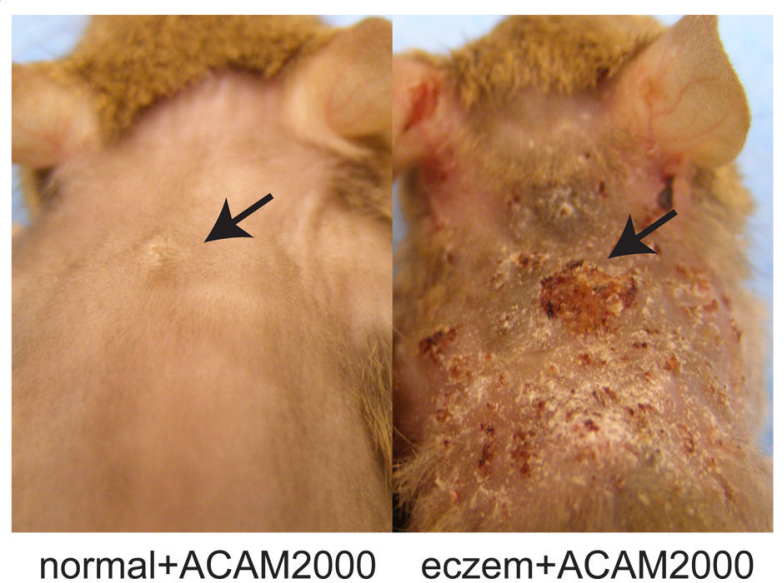

Figure 1. Induction of erosive skin lesions in VACV-infected eczematous mice

(A) Eczematous skin lesions were induced on the shaved back skin of NC/Nga mice by repeated Der f/SEB (D/B) treatments. The mice with eczematous skin lesions and healthy skin mice were intradermally infected with VACV at the back skin. (B) Typical eczematous of skin (right) and normal skin (left) mice. (C) Typical erosive skin lesions of Western Reserve strain (left panel) and ACAM2000 strain (right panel) of VACV infected mice. Arrows show the sites of VACV infection. Eczematous mice with a clinical score of $\geq 7$ were used in the following experiments. 


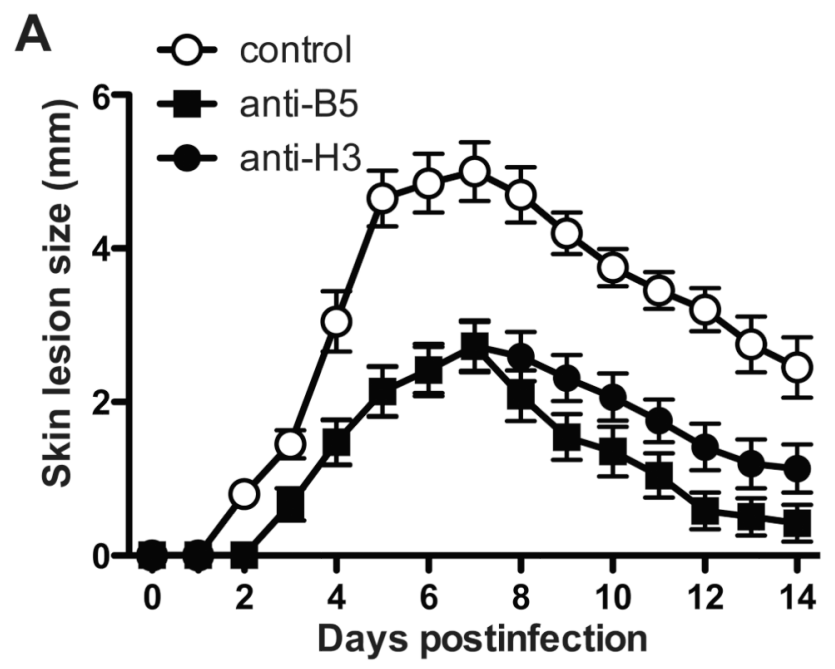

B
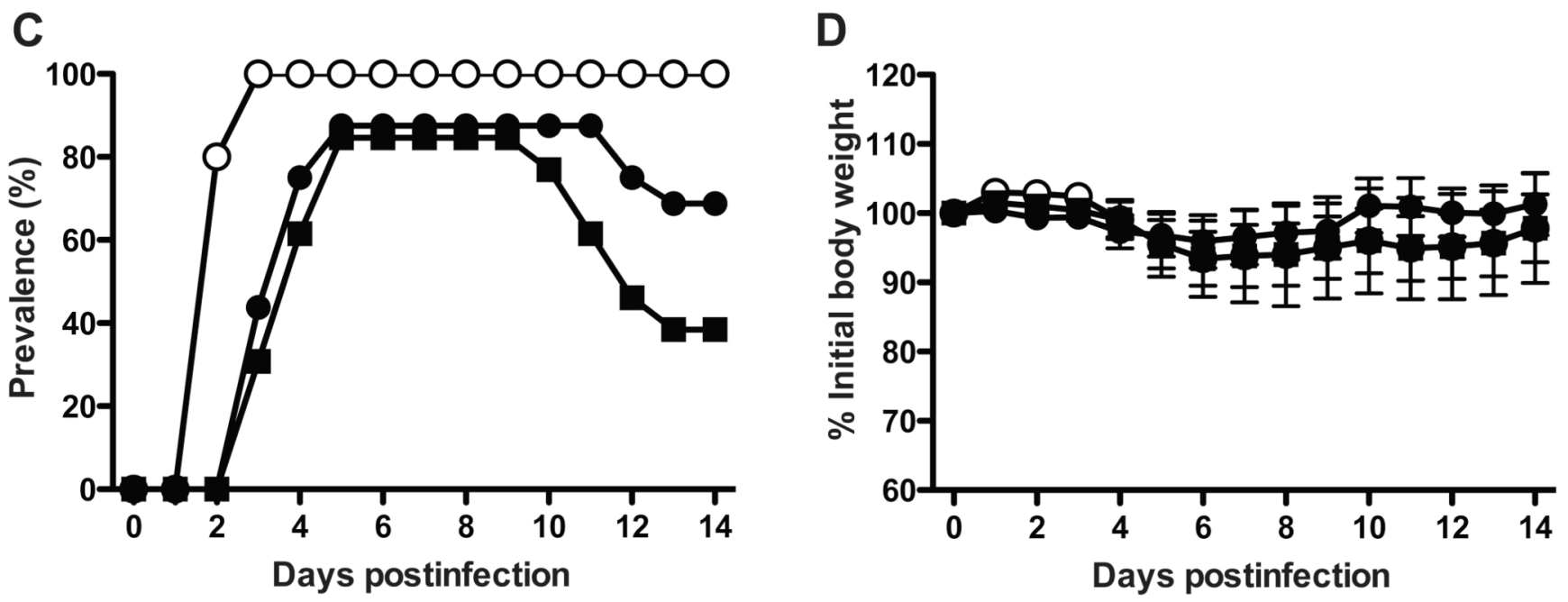

Figure 2. In vivo protection of murine anti-B5 and anti-H3 mAbs injected before VACV infection

(A-D) Eczematous mice were intraperitoneally injected with $200 \mu \mathrm{g}$ of anti-B5 or anti-H3 $\mathrm{mAb} 24 \mathrm{~h}$ before intradermal infection of $1 \times 10^{6} \mathrm{PFU}$ of VACV. PBS was used as control. (A) Development of the skin lesion was observed for 2 weeks and the size of erosive skin lesion was measured. (B) The disease burden calculated from skin lesion size. ***, $\mathrm{P}<$ 0.001 vs. control treated mice. (C) Percentage of mice with skin lesions. (D) The change of body weight after VACV infection. Data represent mean and SEM. N = 10-16 each group and the combined data of 3 independent experiments are shown here. 
A

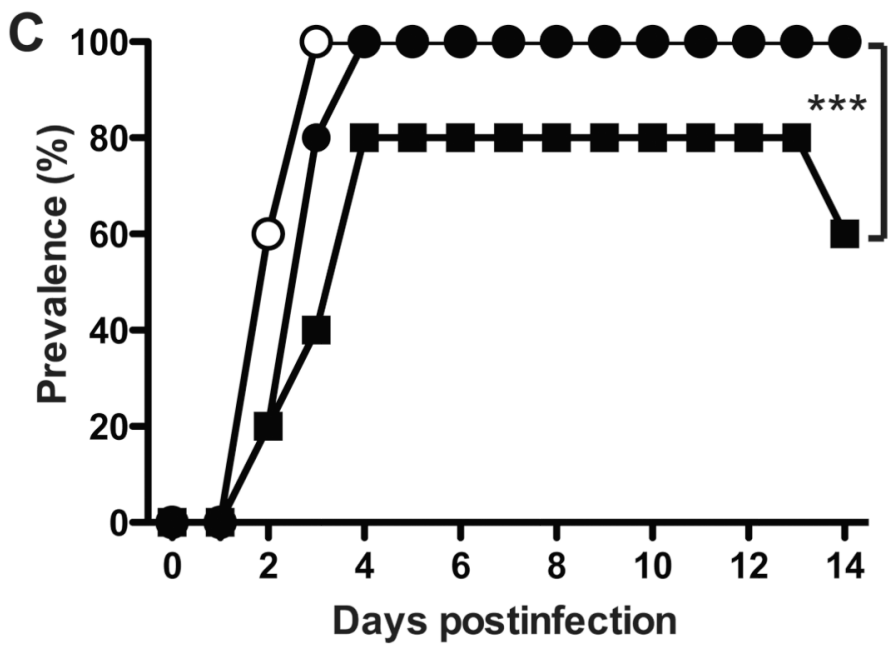

B

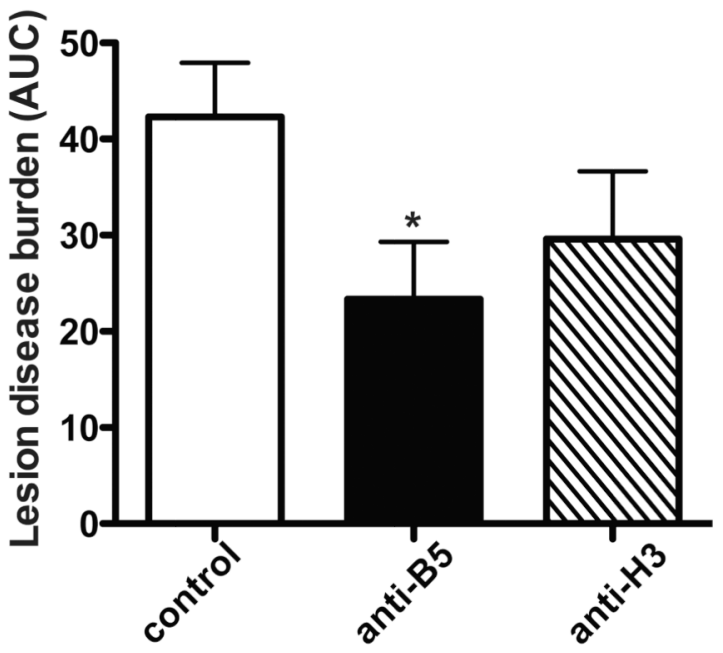

Figure 3. In vivo protection of murine anti-B5 and anti-H3 mAbs injected after VACV infection (A-C) Eczematous mice were intravenously injected with $200 \mu \mathrm{g}$ of anti-B5 or anti-H3 $\mathrm{mAb} 12 \mathrm{~h}$ after intradermal infection of $1 \times 10^{6} \mathrm{PFU}$ of VACV. PBS was used as control treatment. (A) Development of erosive skin lesions was observed for 2 weeks. Data represent mean and SEM values. (B) The disease burden calculated from skin lesion size. *, $\mathrm{P}<0.05$ vs. control treated mice. (C) Percentage of mice with skin lesions. The data represent one of three experiments. $\mathrm{N}=4-7$ per group per each experiment. 


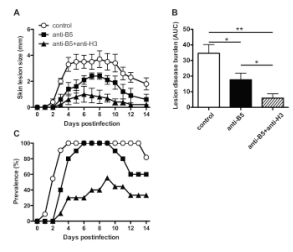

Figure 4. The effect of combined injection of murine anti-B5 and anti-H3 mAbs for development of skin lesions

(A-C) Eczematous mice were intravenously injected with $200 \mu \mathrm{g}$ of anti-B5 or a combination of each $200 \mu \mathrm{g}$ of anti-B5 and anti-H3 mAb $12 \mathrm{~h}$ after intradermal infection of $1 \times 10^{6}$ PFU of VACV with PBS as control. (A) Erosive skin lesion kinetics. (B) The disease burden calculated from skin lesion size. * $* *$ : $\mathrm{P}<0.05, \mathrm{P}<0.01$. The data represent one of two experiments. $\mathrm{N}=5-6$ per group per each experiment. (C) Percentage of mice with skin lesions. Data are the composite of two experiments. $\mathrm{N}=10-12$ per group. 
A

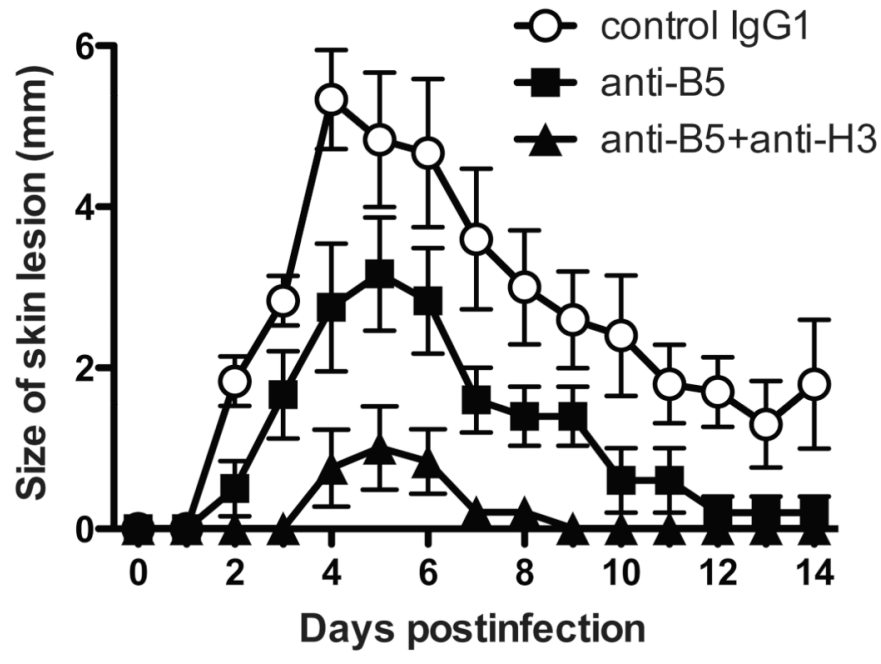

B

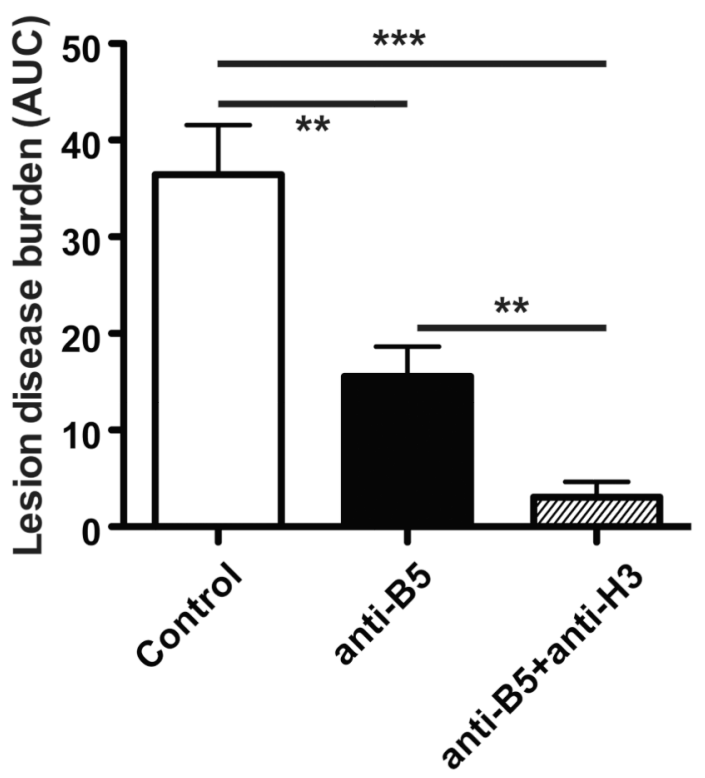

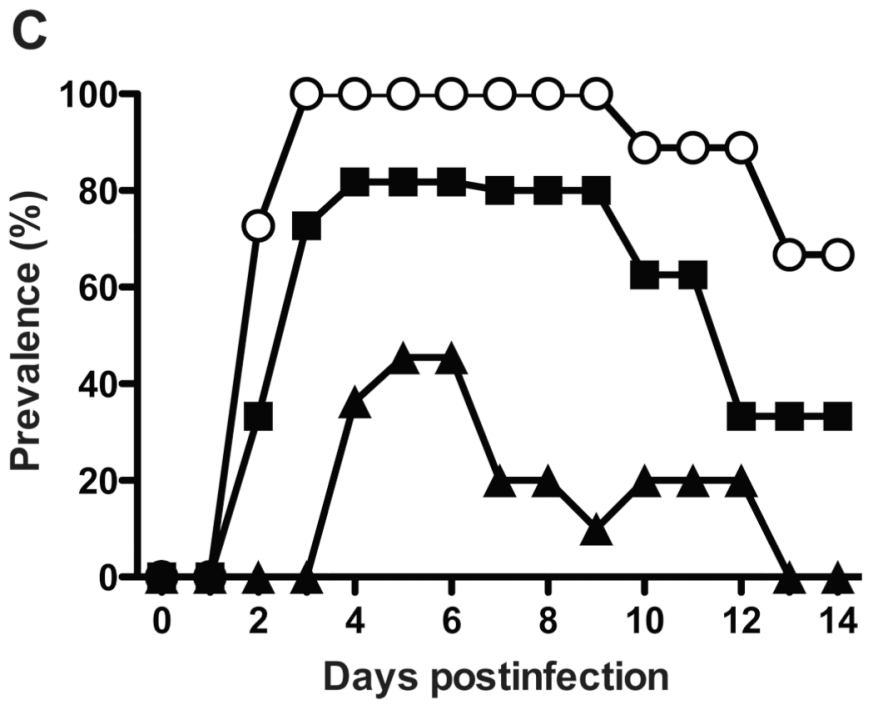

Figure 5. Post-infection treatment with human anti-B5 and anti-H3 mAbs Eczematous mice were intravenously injected with $200 \mu \mathrm{g}$ of anti-B5 or a combination of each $200 \mu \mathrm{g}$ of anti-B5 and anti-H3 mAb $12 \mathrm{~h}$ after intradermal infection of $1 \times 10^{6} \mathrm{pfu}$ of VACV with human anti-DNP IgG1 as control. (A) Skin lesion size. (B) The disease burden calculated from skin lesion size. $*, * *$ : $\mathrm{P}<0.05, \mathrm{P}<0.01$. The data represent one of two experiments. $\mathrm{N}=5-6$ per group per each experiment. (C) Percentage of mice with skin lesions. Data are the composite of two experiments. $\mathrm{N}=10-12$ per group. 